Preprints of the

Max Planck Institute for

Research on Collective Goods

Bonn 2017/16

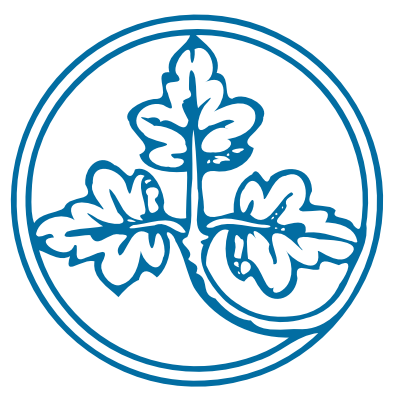

Committing the English and the Continental Way An Experiment

Christoph Engel André Schmelzer

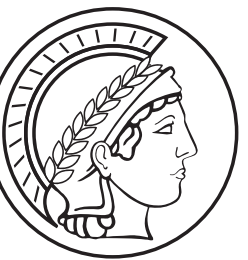




\section{Committing the English and the Continental Way An Experiment}

Christoph Engel / André Schmelzer

August 2017 


\title{
Committing the English and the Continental Way An Experiment ${ }^{*}$
}

\section{Christoph Engel / André Schmelzer}

\begin{abstract}
On the doctrinal surface, there is a deep divide between common and continental law when it comes to the origin of contractual obligations. Under continental law, in principle a unilateral promise suffices. Common law by contrast requires consideration. When it comes to deciding cases, the divide is much less pronounced. But for the most part the law does not govern people's lives through adjudication. It matches or molds their moral intuitions. We test these intuitions in the lab. If consideration is required, participants believe that all participants make more ambitious promises. But they themselves make a more cautious promise. These two effects cancel out, so that promises are not more likely to be kept with consideration.
\end{abstract}

JEL: C91, D02, D03, D12, D64, H41, K12

Keywords: contract, obligation, promise, consideration, experiment, modified dictator game

Helpful input by Michael Kurschilgen, Konstantin Chatziathanasiou, Lars Freund and Anne Sanders is gratefully acknowledged.

corresponding author: Prof. Dr. Christoph Engel, Max Planck Institute for Research on Collective Goods, Kurt-Schumacher-Straße 10, D 53113 Bonn, Germany, engel@coll.mpg.de.

André Schmelzer, same address, schmelzer@coll.mpg.de 


\section{Introduction}

Ultimately, reality trumps philosophy. If one just considers doctrine, in many domains legal orders seem to differ profoundly. Not so rarely, these differences are more than historical contingency, and can be traced back to deep differences in philosophy. Yet if one then compares outcomes, from very different doctrinal starting points, legal orders often come to very similar conclusions. One of the most fundamental differences between common and continental law is no exception to this rule. As a matter of principle, on the European continent a mere promise creates a legal obligation, provided the recipient had reason to see the promise as given with the intention to be bound in law. By contrast, in England (and in principle also in the other common law countries), commitment requires exchange. A pledge to give or to do something can only be enforced if it has been given "in consideration" of some commitment or action of the recipient. Seemingly, the practical implications are huge. On the continent individuals should be wary of a "caveat promittens" principle: don't make a promise if you do not want it to be held against you. By contrast, in England recipients should be wary of a "caveat recipiens" principle: don't trust a promise if you are afraid it might be taken back. Yet if one considers how common and continental law decide the characteristic conflicts of life where the doctrinal difference might matter, the solutions actually come fairly close.

Hence much ado about nothing? Not quite. Adjudication and enforcement are only the ultimate modi operandi of the law. If there is no other way of dissolving a conflict, the parties may go to court. But the legal order expects this to be the rare exception. There are two distinct reasons why this expectation tends to be well founded. First, the parties correctly anticipate the court ruling and bargain "in the shadow of the law" (Mnookin and Kornhauser 1979). Second, the legal rule reflects a construction of the situation, and a normative assessment, that is anyhow prevalent in the community. In the latter case, for the typical conflicts of life, there is no need for explicit legal intervention since the law mirrors the moral intuitions that are prevalent in the community. If the law wants to capitalize on the power of moral intuitions, it is important to get them right.

Despite the similarity of outcomes, it therefore matters for the effectiveness of private law which legal order comes closer to the prevalent normative convictions of the law's subjects. Does the typical subject feel bound by a mere promise? Or does the typical subject see unilateral promise more as an expression of intent, but only feels bound by reciprocal exchange? If the answer to the first question is not outright "no", does the typical individual at least feel bound considerably more intensely if the promise is given in exchange to some counterpromise or action? In this paper, we use experimental methods to answer these questions. Since we ask a basic behavioral question, the inevitable loss in external validity is not severe in our case. The main advantage of a lab experiment is identification from random assignment to treatment. This advantage is particularly valuable for comparative law since observational data from different legal orders hardly ever makes it possible to isolate causal effects (Spamann 2015). 
In a behavioral perspective, an individual may just act in the interest of another person because she feels she should. One motive that would support such action, and that has been studied intensely, is inequity aversion (Fehr and Schmidt 1999, Bolton and Ockenfels 2000). If this individual has made a promise, guilt aversion provides an additional motive (Battigalli and Dufwenberg 2007, Ellingsen, Johannesson et al. 2010). A person may feel guilty just because she falls below her own normative standard. Adam Smith calls this the "jurisdiction of the man within" (Smith 1790: III.2.32) (also see Akerlof and Kranton 2000, Engel and Kurschilgen 2015). If the beneficiary learns about the promise, the desire to uphold a favorable social image provides an additional motive (Andreoni and Bernheim 2009).

In the lab, one is in a position to isolate a further motive. It could result from (positive) reciprocity which, in the experimental literature, is defined as a positive reaction to known or expected intentions of the recipient (Rabin 1993, Charness and Rabin 2002). One sees the effect of pure reciprocity if both the ultimately active and the ultimately passive participant make a promise under the veil of ignorance about their future role, and receive feedback about their counterpart's promise. Then the active participant decides knowing what the passive participant had promised in case she would have assumed the active role. The final motive for acting on behalf of the passive participant is actual exchange. It requires a quid pro quo: either party promises something in reaction to the promise made by the other party. Hence one switches from an unconditional to a conditional promise.

In the experiment, we implement a modified dictator game. In a group of two one participant randomly receives the active role. She may keep her endowment, or give any fraction to the passive recipient. The experimenter doubles the amount given. In all treatments, this decision stage is preceded by a commitment stage. In the Continental treatment, under the veil of ignorance about future roles, either participant is asked how much she promises to give, should she have the active role. In the interest of generating more data, we use the strategy method (Selten 1967) and subsequently ask each participant how much she actually transfers to the passive participant should she have the active role. In the Common I treatment, holding everything else constant, before she decides how much she would transfer if she receives the active role, each player is informed about the promise the other player has made (conditional on having the active role). In the Common II treatment, both participants make both an unconditional and a conditional promise. The conditional promise is elicited the following way: they are asked how much they promise to give, (i) provided they assume the active role, and (ii) the now passive player has unconditionally promised to give $\mathrm{x}$ units. After having made both promises, participants learn the unconditional (but not the conditional) promise of the other participant, and decide how much the transfer in case they are assigned the active role.

In our data, knowing how much the counterpart has promised to give does not increase the likelihood of keeping one's own promise. If individuals can condition their own promise on their counterpart's promise (Common II treatment), they are only more likely to keep their own promise if their counterpart's promise has been fairly moderate. Promise keeping is not significantly explained by risk aversion. However on average $68 \%$ of all promises are kept. 
These findings suggest that the main reason for keeping a promise is neither reciprocity nor a quid pro quo, but a self-image concern: participants feel bad if their action is inconsistent with their words. Promises are in line with the beliefs participants hold about the promises of others. Beliefs are sensitive to treatment: they are highest in the Common II treatment, and higher in the Common I than in the Continental treatment. Taken together, this suggests that participants aim at being in line with the normative expectations in their community.

\section{Comparative Law Background}

Common law and continental law give individuals power to create legally enforceable obligations. In both families of legal orders, the debtor must have voluntarily agreed, and must have known that her declaration of will is creating an obligation in law (Smith and Atiyah 2006: chapter 4.2). Yet common law additionally requires that the obligation is created "in consideration" of some obligation or action of the creditor (Restatement (Second) of Contracts 1981, $\S 71$ ) (Smith and Atiyah 2006: chapter 4.3, Burrows 2013: 8.32).

This additional requirement could potentially create a substantial difference between legal orders (for detail see the two monographs by Rothoeft 1968, Fromholzer 1997). Yet for many situations where the difference might matter, both legal orders actually have found very similar solutions. The most important case is a gift. Under continental law, the naked promise of a good or service is not legally valid, unless notified by a notary public ( $\$ 518$ I 1 German $\mathrm{BGB})$. Yet once the promise has been fulfilled, the good or service cannot be asked back (§ 518 II German BGB). In common law, a naked promise lacks consideration. But consideration can be replaced by a deed, i.e. by commitment "under seal" (Smith and Atiyah 2006: chapter 3.2). And a gift cannot be asked back for ingratitude (more from Lee 2012).

Under continental law, a unilateral promise can be enforced in court if it has been pledged as a reward for a future favor, say finding a lost good ( $\$ 657$ German BGB). Common law reaches the same result on a different doctrinal path. As soon as another person has begun fulfilling the action for which the reward has been stipulated, the offeror is prevented from revoking the offer (Daulia Ltd. v. Four Millbank Nominess Ltd. [1978] Ch. 213).

On the continent, the promise to take care of a good owned by another person creates an enforceable obligation ( $\S 688$ German BGB). The caretaker is held liable if she neglects the good. Only the standard of care is reduced to the same effort as in her own affairs $(\S 690$ German BGB). Common law solves the case by constructing consideration. It suffices for an exchange that the owner has allowed the promisor to possess the good (Coggs v. Bernard 92 Eng.Rep. 107 (1703)).

On the continent, the promise to fulfil some action that is in the interest of another person is enforceable, even if there is no remuneration ( $\S 662$ German BGB). Yet the promisor may take the promise back at any time ( $\$ 671$ I German BGB). She may, however, only do so in a 
way that makes it possible for the recipient to find a replacement ( $\$ 671$ II 1 German BGB). Under common law, for want of consideration in principle there is no obligation. Yet in equity, promissory estoppel obliges the promisor to give notice that she will not perform, or to exercise due care, if she realizes that the promisee will reasonably rely on the promise $(\S 378$ Restatement (Second) of Agency).

There are some real differences though. Under Swiss law, the promise to bestow a chattel on another person only needs to be given in writing to be enforceable (Art 243 I Swiss OR). Under German law, simple written form suffices if one person promises to pay a pension to another person ( $\S 761,1$ German BGB). Under continental law, prenuptial agreements are enforceable as any other contract ( $§ 1408$ German BGB), while common law still wrestles with them, arguing that they lack consideration (for detail see Biemiller 2013). Another true difference concerns an offer to conclude a contract. Under German law, as a default a person issuing an offer is bound by it, $\S 145$ BGB. Under common law, however, the person issuing an offer is free to revoke it unless it has been given "in consideration" of some counter-promise or action (Dickinson vs. Dodds [1876] 2 Ch D 463; Nielsen vs. Dysart Timbers Ltd. [2009] NZSC 43).

\section{Earlier Findings}

The literature that rigorously tests the behavioral underpinnings of contract law is still small. Laypersons believe that a contract is binding once it has been written up and signed, or if it has been fulfilled (Wilkinson-Ryan and Hoffman 2015). If participants had been given the option to opt into a purportedly contractual obligation, they are more likely to fulfil this obligation (Eigen 2012). Closest to our experiment is the study by Eigen and Hoffman (2015). In two separate designs, they test Amazon M-Turk participants on one of two tasks: allocating an endowment to one of two charities, and choosing between two proposals for the marketing of a book. Irrespective of treatment, participants are paid for participation. Participants first fulfill the respective task. After completing filler tasks, they are given the opportunity to "back out" from their earlier decision, and keep some of the money for themselves. The main dependent variable is the back out rate. In the charities task it is smallest if the computer program explicitly mentions "consideration", and gives participants an additional monetary bonus to be "committed" to the allocation they had made before. In the marketing task, however, the back out rate is smallest if the vignette mentions "consideration", but no bonus is given. Essentially, this experiment does not test consideration (it is present in all treatments, since individuals are paid for participation), but recitals, i.e. making commitment explicit, and tying it to an additional symbolic payment. Also the dependent variable is not the initial promise, but resisting the surprise temptation to neglect an earlier decision.

The behavioral economics literature finds that non-binding promises increase cooperation (e.g. Ellingsen and Johannesson 2004). The debate centers around the question why individu- 
als keep their promises in the first place. Two explanations compete: Either individuals have a preference for keeping the promise per se (Vanberg 2008) and feel committed (Charness and Dufwenberg 2010, Ellingsen, Johannesson et al. 2010), or their behavior is driven by expectations and guilt aversion (Charness and Dufwenberg 2006, Battigalli and Dufwenberg 2007, Ederer and Stremitzer 2016). It has been argued that it depends on social closeness which of these two explanations is critical (Morell 2015).

\section{Design and Hypotheses}

The main experiment has two stages. All participants know that the second stage of the experiment will be a modified dictator game. The dictator receives an endowment of 1200 tokens. She is free to keep the endowment for herself, or to share any number of tokens with the recipient. Any token that the dictator shares is doubled up by the experimenter. At the first stage of the experiment, participants are randomly matched to groups of two. Yet it is not determined which of them will have the active and which the passive role at the second stage of the experiment. Participants have the possibility to promise how many tokens they will share with the other group member, should they have the active role. We have three treatments, meant to match the moral intuitions corresponding to the doctrinal difference between continental and common law. In the Continental treatment, promises are registered, but not communicated. This excludes that promises serve as a technology to signal intentions to one's counterpart. Promises are, however, framed as promises to the other group member, not as promises to the experimenter. This treatment captures the motivating effect of self-image (on the motivating effect of self-image effect see Engel and Kurschilgen 2015).

In the Common I treatment, we add one more piece of information. Before they decide how much to transfer, participants learn what their counterpart has promised to do should she be assigned the active role. Using the strategy method, each participant then decides how much to transfer, conditional on being singled out as dictator. If we find a difference between the Continental and the Common I treatments, we can conclude that the effect results from a concern for reciprocity in promises (on the motivating effect of reciprocity see e.g. Rabin 1993, Falk and Fischbacher 2006).

In the Common II treatment, we ask each participant to make two promises: one unconditional as in the other treatments, and a second promise that conditions on the unconditional promise made by the other group member. For the latter choice, we use the strategy method (Selten 1967). We give participants 12 thresholds, running from 0 to 1100 tokens, and ask them about their own promise, conditional on the other participant's unconditional promise being at least $\mathrm{x}$ tokens. At the second stage of the experiment - exactly as in the Common I treatment and before deciding how much to transfer - both participants learn the unconditional promise of the other participant. Hence technically the only difference between the Common I and the Common II treatments results from the fact that participants have made two promises before 
they learn the unconditional promise of their counterpart: the unconditional and the conditional promise. In the analysis, we focus on the relationship between the conditional promise, given the counterpart's unconditional promise, and the decision how much to transfer (should this participant be assigned the active role). We thus measure the likelihood that a participant violates her own promise that she had given in response to her counterpart's unconditional promise. If we find a difference between the Common I and the Common II treatments, we know that an exchange of promises is critical for fulfilling a promise.

At all points of the experiment, and in particular when deciding how much to transfer, participants could revisit their promise, by clicking a button on the computer screen. This design feature is meant to rule out the option to "forget" a more demanding promise.

The design is analogous to a joint venture. Ex ante, both group members know that they face an uncertain environment. They anticipate that the ability to exploit a profitable opportunity will be asymmetrically distributed. If group members make a promise, this can be interpreted as the stated willingness to exploit this opportunity in the collective, rather than their individual interest. In the Common II treatment, there is true exchange (of promises; not of actions). To the degree that she promises sharing part of her endowment, the later active participant gives up part of her ability to maximize her own profit in exchange against the passive participant's unconditional promise. Note that, in this game, exchange is taking place at the first, not at the second stage (which is unilateral).

Recall that the purpose of our experiment is not to create an enforceable contract in the lab. We deliberately do not create any enforcement option. We refrain from asking whether participants feel bound in law. We thus bracket the distinction between comity and law. We do so in the interest of cleanly identifying the moral intuitions underlying mutually beneficial exchange. We exclude law students since we want to investigate the moral intuitions in the population, not the effect of legal education on incentivized choices.

Our main dependent variable is promise keeping. If continental law captures the essence of moral intuitions, and if the key motivating factor is self image, we should not see treatment effects. If commitment is essentially created by reciprocity, we should find a difference between Continental and Common I. If a promise must be backed up by an exchange of promises to create moral commitment, there should be a difference between Common I and Common II.

We are open to the possibility that a measurable commitment effect categorically requires any of these motivating forces to be at work. This would imply that promise keeping is not significantly different from zero as long as the critical motive is not activated. Yet effects need not be categorical. It could also be that exchange has a stronger commitment effect than mere reciprocity than mere self image. Then continental law would not completely get it wrong. But common law would rely on a mechanism that creates a stronger bond. 
While our prime interest is in promise keeping, we are also interested in promise giving. Does a more effective commitment mechanism make individuals more cautious when giving promises?

Hence we test

$\mathbf{H}_{1}$ : Participants are more likely to keep promises in Common II than in Common I than in Continental.

$\mathbf{H}_{2}$ : Participants make less ambitious promises in Common II than in Common I than in Continental.

After the main experiment, we elicit two beliefs (and incentivize participants for their statements). We ask them how much they believe all the participants in their respective session have promised to transfer if they are assigned the active role, and how much they have actually transferred. We also measure social value orientation using the design developed by Murphy and Ackermann (2014), risk preferences (Holt and Laury 2002), and justice sensitivity (Schmitt, Baumert et al. 2010). ${ }^{1}$

180 participants have been selected from the pool of the Bonn EconLab of about 6000. 63 $(35 \%)$ were male. Most of them were students, with various majors. Since we are interested in moral intuitions in the population, not in the effects of legal education on these intuitions, we have excluded law students from the experiment. Mean age was 24.17 years. We had 66 participants in the Continent and Common I treatments, and 48 in the Common II treatment. Sessions lasted around 45 minutes. Participants on average earned $15.89 €$ (equivalent of 17.27\$ on the first day of the experiment), $13.91 €$ if they were randomly selected as the passive player, and $17.87 €$ in the active role. The experiment was programmed in zTree (Fischbacher 2007). Participants were invited using hroot (Bock, Baetge et al. 2014).

\section{Results}

Table 1 summarizes results. Our main variable of interest is promise keeping. As Table 1 shows, we have a surprising finding: conditional promises are not more obeyed (as we had expected), but descriptively even less. Yet this difference is not significant at conventional levels, neither non-parametrically nor parametrically. Overall we thus reject $\mathrm{H} 1$ and do not find support for the claim that common law better matches participants' moral intuitions than continental law. ${ }^{2}$

None of these additional measures explains the data, though.

We have most statistical power for comparing the Continental with both Common treatments pooled. If we allow for a $\beta$ error of at most $20 \%$ (i.e. use a test with $80 \%$ power), we can exclude an effect of size .446 (Cohen's d). This is regarded as a small effect, (Cohen 1992). We are therefore entitled to interpret the non-effect. 


\begin{tabular}{|l|c|c|c|c|c|}
\hline & \% keeps promise & promise & transfer & belief promise & belief transfer \\
\hline Continental & 71.21 & 306.26 & 244.95 & 296.71 & 231.08 \\
\hline Common I & 68.18 & 328.03 & 272.73 & 336.68 & 264.53 \\
\hline Common II & 64.58 & 285.06 & 277.92 & 347.21 & 281.58 \\
\hline
\end{tabular}

Table 1

Descriptive Statistics

We conclude

Result 1: If participants know how much a counterpart has promised to give, and if they can condition their own promise on this information, they are not more likely to keep their promise.

We do however find a significant effect if we control for the size of the counterpart's promise, and interact the Common II treatment with this control variable (Table 2 Model 3). ${ }^{3}$ Since this control variable is only meaningful for the Common treatments, this analysis is confined to them. The effect is positive. As hypothesized $\left(\mathbf{H}_{1}\right)$, promises are more likely to be kept if they are given in exchange against a counterpromise. Yet this effect only holds if the counterpromise is fairly moderate. Through the interaction effect, the treatment effect reverses as soon as the counterpromise is 313 units, or more demanding. ${ }^{4}$ This effect is not resulting from the fact that more demanding promises are less trusted: in model 4 we do find that a participant is the more likely to keep her own promise the more she expects her counterpart had transferred had she been given the active role. Yet the interaction effect is clearly insignificant: participants do not trust more demanding participants less. The more a promise is demanding, the less it is likely to be kept, irrespective of treatment (Model 5). Interestingly, risk aversion has no explanatory power (Model 6). We therefore find that the expected mechanism driving hypothesis $\mathbf{H}_{\mathbf{1}}$ is clearly not at work: participants are not scared off by the behavioral uncertainty about their counterpart.

3 Since the interaction effect(s) are critical for the analysis, we estimate a linear probability model. As is well known, in non-linear models interaction effects cannot be directly interpreted, and average significance is not necessarily informative either (Ai and Norton 2003). 


\begin{tabular}{|c|c|c|c|c|c|c|}
\hline & $\begin{array}{l}\text { model } \\
1\end{array}$ & $\begin{array}{l}\text { model } \\
2\end{array}$ & model 3 & model 4 & model 5 & model 6 \\
\hline Common II & $\begin{array}{l}-.036 \\
(.090)\end{array}$ & $\begin{array}{l}-.042 \\
(.486)\end{array}$ & $\begin{array}{l}.626^{* *} \\
(.192)\end{array}$ & $\begin{array}{l}.512^{\star *} \\
(.191)\end{array}$ & $\begin{array}{l}.454^{*} \\
(.217)\end{array}$ & $\begin{array}{l}.482^{*} \\
(.234) \\
\end{array}$ \\
\hline other's promise & & $\begin{array}{l}.0006^{*} \\
(.0003)\end{array}$ & $\begin{array}{l}.0015^{* * *} \\
(.0004)\end{array}$ & $\begin{array}{l}.0016^{* *} \\
(.0006)\end{array}$ & $\begin{array}{l}.0015^{* * *} \\
(.0004)\end{array}$ & $\begin{array}{l}.0017^{* * *} \\
(.0003)\end{array}$ \\
\hline Common $I{ }^{*}$ other's promise & & & $\begin{array}{l}-.0020^{* * \star} \\
(.0005)\end{array}$ & $\begin{array}{l}-.0017^{* \star} \\
(.0005)\end{array}$ & $\begin{array}{l}-.0012^{*} \\
(.0005) \\
\end{array}$ & $\begin{array}{l}-.0013^{*} \\
(.0005) \\
\end{array}$ \\
\hline expected transfer by counterpart & & & & $\begin{array}{l}.0017^{*} \\
(.0008)\end{array}$ & & \\
\hline $\begin{array}{l}\text { other's promise * expected transfer } \\
\text { by counterpart }\end{array}$ & & & & $\begin{array}{l}-.000002 \\
(.000002)\end{array}$ & & \\
\hline own promise & & & & & $\begin{array}{l}-.0011^{* *} \\
(.0003)\end{array}$ & $\begin{array}{l}-.0012^{* *} \\
(.0003)\end{array}$ \\
\hline Common $1{ }^{*}$ own promise & & & & & $\begin{array}{l}-.0005 \\
(.0006)\end{array}$ & $\begin{array}{l}-.0003 \\
(.0006)\end{array}$ \\
\hline constant relative risk aversion & & & & & & $\begin{array}{l}.004 \\
(.095)\end{array}$ \\
\hline $\begin{array}{l}\text { Common } I{ }^{*} \text { constant relative risk } \\
\text { aversion }\end{array}$ & & & & & & $\begin{array}{l}-.070 \\
(.180)\end{array}$ \\
\hline cons & $\begin{array}{l}.682^{* * *} \\
(.059)\end{array}$ & $\begin{array}{l}.495^{* * *} \\
(.107)\end{array}$ & $\begin{array}{l}.176 \\
(.131)\end{array}$ & $\begin{array}{l}-.075 \\
(.191)\end{array}$ & $\begin{array}{l}.539^{* *} \\
(.165)\end{array}$ & $\begin{array}{l}.501^{* *} \\
(.170)\end{array}$ \\
\hline $\mathrm{N}$ & 114 & 114 & 114 & 114 & 114 & 108 \\
\hline
\end{tabular}

Table 2

Explaining Promise Keeping in Common Treatments

Linear Probability Model

$\mathrm{dv}$ : a dummy that is 1 if transfer $\geq$ promise (in Common // treatment: $\geq$ conditional promise) model 5: data from 6 participants dropped who were inconsistent on Holt/Laury measure standard errors in parenthesis

${ }^{* * *} p<.001,{ }^{* *} p<.01,{ }^{*} p<.05,{ }^{+} p<.1$

A promise is kept if the transfer is at or above the promise. Figure 1 shows that there is considerable variance..$^{5}$ If a participant exactly acts as stated, choices are on the $45^{\circ}$ line. In all treatments, we find many choices at 400/400. If the active player transfers 400 tokens, profit is split equally: the active participant keeps 800; what the passive participant receives is doubled up by the experimenter. A substantial minority make generous promises, but do not transfer anything. These choices are on the horizontal zero line. Any choice below the $45^{\circ}$ line is a broken promise. Interestingly, a considerable fraction of participants transfer even more than they had promised. Their choices are above the $45^{\circ}$ line. If participants have learned the promise of their counterpart before deciding how much to transfer (Common treatments), this can be the reason. It is in line with the fact that, in Table 2, we find a significant positive effect of the counterpart's promise on the probability that a promise is kept. There are, however, also a number of transfers above the promise in the Continental treatment. In this treatment, participants do not know their counterpart's promise when deciding how much to transfer. This suggests that the mere beliefs about the promises of others also have a positive effect (cf. Table 4).

5 To increase readibility, in the graphs promises and transfers are in bins of 100 . This also explains why, in the Continental and in the Common II treatments, there are seemingly choices that keep and that break the promise at the same point. 


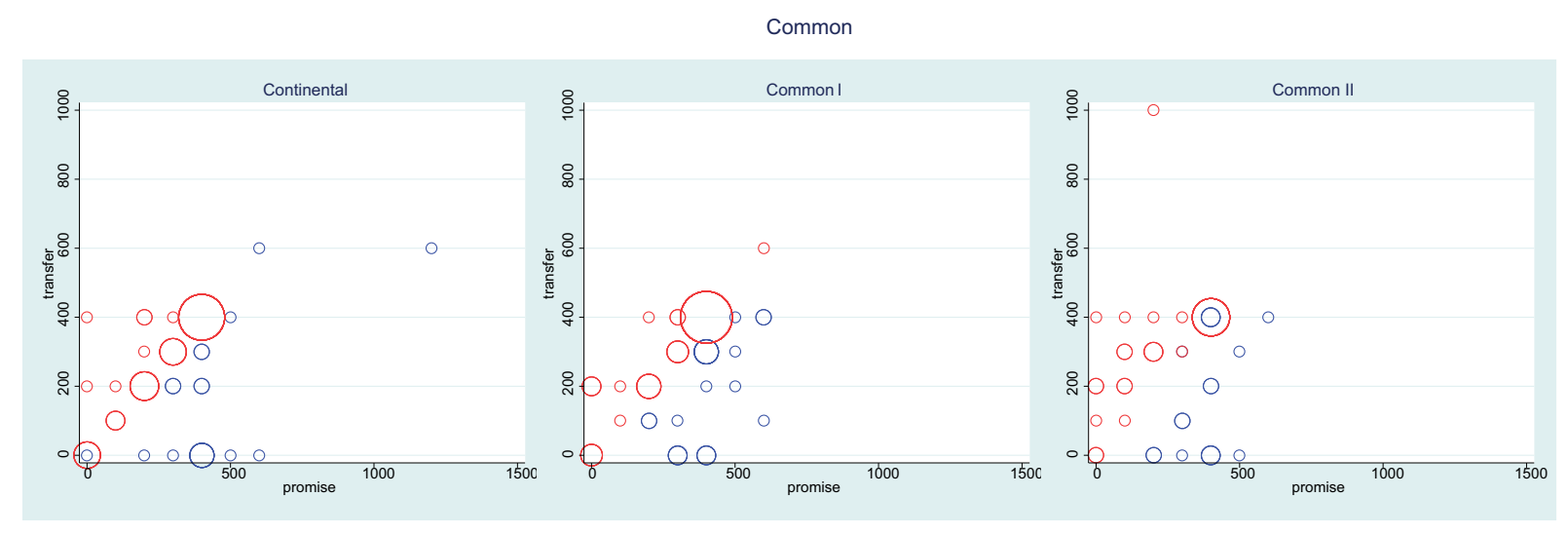

Figure 1

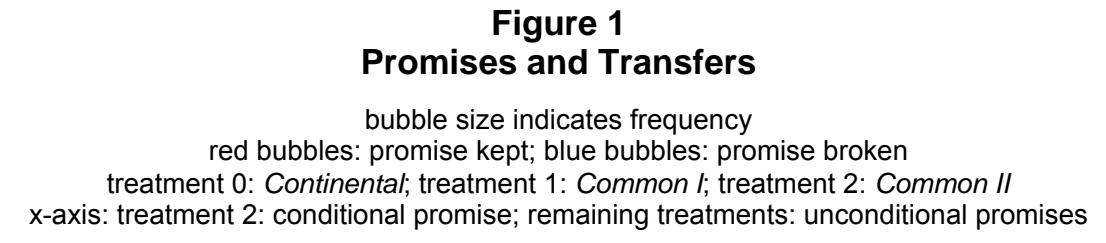

As the regressions of Table 3 show, the picture clears if we take the beliefs into account that individuals hold about the promises others make. There is not only a strong positive correlation between beliefs and participants' own promises (model 2). Once we control for these beliefs, we also find treatment effects. If individuals are pessimistic about the promises made by others, treatments do have an effect. Descriptively, promises are more generous in the Common II than in the Common I than in the Continental treatment. The difference between the Continental and the Common II treatment is significant at conventional levels: if participants can condition their promises on their counterpart's promise and if they are pessimistic about the promises of others, they make more generous promises. However there is also a highly significant negative interaction effect (Model 3). If participants believe that dictators on average promise to give 226 or more, the advantage of the Common II treatment reverses. ${ }^{6}$ With this proviso, we support $\mathbf{H}_{2}$ : provided participants are at least mildly optimistic about the promises made by others, conditional promises are more cautious. 


\begin{tabular}{|l|l|l|l|}
\hline & model 1 & model 2 & model 3 \\
\hline Common I & 21.773 & -7.655 & $125.916^{+}$ \\
& $(28.530)$ & $(25.098)$ & $(71.348)$ \\
\hline Common II & -21.195 & $-58.372^{*}$ & $141.170^{*}$ \\
& $(32.102)$ & $(27.439)$ & $(70.086)$ \\
\hline belief about promises & & $.736^{* * *}$ & $1.065^{* * *}$ \\
& & $(.086)$ & $(.136)$ \\
\hline Common I belief & & & $-.436^{*}$ \\
& & & $(.209)$ \\
\hline Common II ${ }^{*}$ belief & & & $-.623^{* *}$ \\
& & & $(.200)$ \\
\hline cons & $306.258^{* * *}$ & $87.807^{* *}$ & -9.866 \\
& $(20.831)$ & $(31.091)$ & $(43.790)$ \\
\hline $\mathrm{N}$ & 180 & 180 & 180 \\
\hline
\end{tabular}

Table 3

Explaining Promises

OLS

standard errors in parenthesis

${ }^{\star * *} p<.001,{ }^{* *} p<.01,{ }^{*} p<.05,{ }^{+} p<.1$

We conclude

Result 2: Provided participants believe promises in the population to be near the equal split or higher, promises are more cautious if participants can condition promises on the promise made by their counterpart.

In the next step, we explore the effect of treatments on beliefs. Here we find a clear treatment effect: participants' beliefs are higher in Common II than in Common I than in Continental. The difference between Continental and Common II is significant at conventional levels. This suggests that participants are more disposed towards believing that others are affected by reciprocity and the exchange of promises than they themselves.

\begin{tabular}{|l|l|}
\hline Common I & $\begin{array}{l}39.970^{+} \\
(21.619)\end{array}$ \\
\hline Common II & $\begin{array}{l}50.496^{*} \\
(23.559)\end{array}$ \\
\hline cons & $\begin{array}{l}296.712^{* * \star} \\
(15.287)\end{array}$ \\
\hline $\mathrm{N}$ & 180 \\
\hline
\end{tabular}

Table 4

Explaining Beliefs about Promises

OLS

standard errors in parenthesis

${ }^{* * *} p<.001,{ }^{* *} p<.01,{ }^{*} p<.05,{ }^{+} p<.1$ 
We conclude

Result 3: If participants know that they learn the promise made by their counterpart before deciding how much of their endowment to transfer, they believe that more generous promises are made.

In the final step, we put the individual pieces together and estimate a structural model, Table 5. Also when jointly estimating transfers, promises and beliefs, we do not find any (direct) treatment effect on transfers. Transfers are, however, significantly predicted by promises: the more a participant has promised to transfer, the more she transfers. Yet the coefficient is only .428. The statistical model predicts that a promise that is 1 unit more demanding only increases actual transfers by .428 units. Promises are in turn predicted by beliefs. The more a participant believes that others promise, the more she promises herself. This correlation is quite pronounced. We do, however, find a first treatment effect: in the Common II treatment, promises are significantly more cautious. By contrast, in both Common treatments, participants believe that others make more demanding promises. The effect of the Common II treatment on beliefs is significant at conventional levels. The structural model makes it possible to also test for the significance of indirect effects. We find a significant negative indirect effect of the Common II treatment on transfers through promises, ${ }^{7}$ and a significant (twice) indirect positive effect of the Common II treatment on transfers through beliefs and promises. ${ }^{8}$ Yet these two effects cancel each other out. ${ }^{9}$ Hence the Common II treatment pulls participants in two opposite directions: they believe that others will be swayed, but they respond by becoming more cautious themselves.

7 Effect of Common II on promises * effect of promises on transfers, $-24.959, \mathrm{p}=.042$,

8 Effect of Common II on beliefs * effect of beliefs on promises * effect of promises on transfers, 15.896, p $=.048$

9 Net effect of the once and the twice indirect effect on transfers, $-9.062, \mathrm{p}=.508$. 


\begin{tabular}{|l|l|}
\hline transfer & \\
\hline promise & $.428^{\star * *}$ \\
& $(.068)$ \\
\hline Common I & 18.463 \\
& $(26.461)$ \\
\hline Common II & 42.025 \\
& $(28.826)$ \\
\hline cons & $114.006^{* * *}$ \\
& $(28.053)$ \\
\hline promise & \\
\hline belief about promises & $.736^{\star * *}$ \\
& $(.092)$ \\
\hline Common I & -7.654 \\
& $(24.856)$ \\
\hline Common II & $-58.372^{*}$ \\
& $(27.118)$ \\
\hline cons & $87.807^{* * *}$ \\
& $(32.405)$ \\
\hline belief about promises & \\
\hline Common I & $39.970^{+}$ \\
\hline Common II & $(21.438)$ \\
\hline cons & $50.496^{*}$ \\
& $(23.362)$ \\
\hline $\mathrm{N}$ & $296.712^{* * *}$ \\
\hline & $(15.159)$ \\
\hline & 180 \\
\hline
\end{tabular}

Table 5

Effect of Treatment on Beliefs, Promises, and Choices

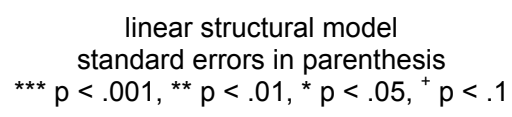

We conclude

Result 4: If participants know that they learn the promise made by their counterpart before deciding how much of their endowment to transfer, this has two indirect effects on transfers:

a) they believe that others make more demanding promises

b) they make less demanding promises themselves

Both indirect effects cancel out.

\section{Discussion}

Our experiment has been motivated by a deep doctrinal divide between continental and common law. While in common law, a legal obligation requires "consideration", a quid pro quo, in principle on the continent a mere promise is binding, provided it has been given expecting that the recipient has understood it as binding in law. One might have thought that common law better captures prevalent moral intuitions. At least one might have thought that a promise 
that is given in exchange for a counterpromise is regarded as a stronger commitment, and therefore less likely to be broken. Against this backdrop, we have a surprising finding. In our experiment, conditional promises are not kept better than unconditional promises. We have no support for common law doctrine being preferable since it is more in line with participants' moral intuitions.

Every experiment has limitations. We test students, not representative agents. Yet contracts are ubiquitous. Every day, a student concludes multiple contracts. We see no reason to expect the moral intuitions of students to be fundamentally different from the moral intuitions of other members of the population. We have run the experiment in Germany, i.e. in a continental law country. We cannot exclude that the position of German law on the issue has found its way into moral intuitions that are prevalent in the country. The only way to check would be replicating the experiment in a common law country.

The doctrine of consideration does not require an exchange of goods, services or money. An exchange of promises suffices. The quid pro quo may only exist in expectation, not in execution. Therefore the fact that our experiment randomly assigns the active and the passive role after participants have made their promises is in keeping with common law. Yet behaviorally it might be that participants have been less influenced by the risk of being let down by their counterpart since this risk has been overshadowed by the uncertainty regarding the active vs. the passive role. But if this behavioral effect had been critical, at least for a mere exchange of promises, common law could not rely on moral intuitions.

Doctrine is a legacy of history. It is not designed in an engineering fashion. Effective governance is only one concern for those who engage in developing doctrine. We do therefore not want to make a normative claim. But we note that, at least with the design of our experiment, we could not find that the approach taken by common law outperforms the approach taken by continental law. If doctrine is built on the idea that mere promises can be enforced, this does not clash with individuals' moral intuitions. 


\section{References}

Ai, Chunrong and Edward C. Norton (2003). "Interaction Terms in Logit and Probit Models." Economics Letters 80: 123-129.

Akerlof, George A. and Rachel E. Kranton (2000). "Economics and Identity." Quarterly Journal of Economics 115: 715-753.

Andreoni, James and B. Douglas Bernheim (2009). "Social Image and the 50-50 Norm. A Theoretical and Experimental Analysis of Audience Effects." Econometrica 77: 1607-1636.

Battigalli, Pierpaolo and Martin Dufwenberg (2007). "Guilt in Games." American Economic Review 97(2): 170-176.

Biemiller, Chelsea (2013). "The Uncertain Enforceability of Prenuptial Agreements: Why the Extreme Approach in Pennsylvania Is the Right Approach for Review." Drexel Law Review 6: 133-176.

Bock, Olaf, Ingmar Baetge and Andreas Nicklisch (2014). "hroot: Hamburg Registration and Organization Online Tool." European Economic Review 71: 117-120.

Bolton, Gary E. and Axel Ockenfels (2000). "ERC: A Theory of Equity, Reciprocity and Competition." American Economic Review 90: 166-193.

Burrows, Andrew (2013). English Private Law, Oxford University Press.

Charness, Gary and Martin Dufwenberg (2006). "Promises and Partnership." Econometrica 74(6): 1579-1601.

Charness, Gary and Martin Dufwenberg (2010). "Bare Promises. An Experiment." Economics Letters 107(2): 281-283.

Charness, Gary and Matthew Rabin (2002). "Understanding Social Preferences with Simple Tests." Quarterly Journal of Economics 117: 817-869.

Cohen, Jacob (1992). "A Power Primer." Psychological Bulletin 112(1): 155-159.

Ederer, Florian and Alexander Stremitzer (2016). Promises and Expectations.

Eigen, Zev (2012). "When and Why Individuals Obey Form-Adhesive Contracts. Experimental Evidence of Consent, Compliance, Promise and Performance." Journal of Institutional and Theoretical Economics 168: ***.

Eigen, Zev and David Hoffman (2015). Contract Consideration and Behavior. 
Ellingsen, Tore and Magnus Johannesson (2004). "Promises, Threats and Fairness." Economic Journal 114(495): 397-420.

Ellingsen, Tore, Magnus Johannesson, Sigve Tjotta and Gaute Torsvik (2010). "Testing Guilt Aversion." Games and Economic Behavior 68: 95-107.

Engel, Christoph and Michael Kurschilgen (2015). The Jurisdiction of the Man Within. Introspection, Identity, and Cooperation in a Public Good Experiment.

Falk, Armin and Urs Fischbacher (2006). "A Theory of Reciprocity." Games and Economic Behavior 54: 293-315.

Fehr, Ernst and Klaus M. Schmidt (1999). "A Theory of Fairness, Competition, and Cooperation." Quarterly Journal of Economics 114: 817-868.

Fischbacher, Urs (2007). "z-Tree. Zurich Toolbox for Ready-made Economic Experiments." Experimental Economics 10: 171-178.

Fromholzer, Ferdinand (1997). Consideration. Tübingen, Mohr (Siebeck).

Holt, Charles A. and Susan K. Laury (2002). "Risk Aversion and Incentive Effects." American Economic Review 92: 1644-1655.

Lee, Ruth Sarah (2012). "A Legal Analysis of Romantic Gifts." University of Miami Law Review 67: 595-635.

Mnookin, Robert H. and Lewis A. Kornhauser (1979). "Bargaining in the Shadow of the Law." Yale Law Journal 88: 950-997.

Morell, Alexander (2015). The Short Arm of Guilt: Guilt Aversion Plays Out More Across a Short Social Distance.

Murphy, Ryan O. and Kurt A. Ackermann (2014). "Social Value Orientation: Theoretical and Measurement Issues in the Study of Social Preferences." Personality and Social Psychology Review 18: 13-41.

Rabin, Matthew (1993). "Incorporating Fairness into Game Theory and Economics." American Economic Review 83: 1281-1302.

Rothoeft, Dietrich (1968). System der Irrtumslehre als Methodenfrage der Rechtsvergleichung. Dargestellt am deutschen und englischen Vertragsrecht. Tübingen, Mohr Siebeck.

Schmitt, Manfred, Anna Baumert, Mario Gollwitzer and Jürgen Maes (2010). "The Justice Sensitivity Inventory. Factorial Validity, Location in the Personality Facet Space, 
Demographic Pattern, and Normative Data." Social Justice Research 23(2-3): 211238.

Selten, Reinhard (1967). Die Strategiemethode zur Erforschung des eingeschränkt rationalen Verhaltens im Rahmen eines Oligopolexperiments. Beiträge zur experimentellen Wirtschaftsforschung. E. Sauermann. Tübingen, Mohr: 136-168.

Smith, Adam (1790). The Theory of Moral Sentiments, or, An Essay Towards an Analysis of the Principles by which Men Naturally Judge Concerning the Conduct and Character, First of Their Neighbours, and Afterwards of Themselves. To which is Added, a Dissertation on the Origin of Languages. London, Strahan.

Smith, Stephen A and Patrick S Atiyah (2006). Atiyah's Introduction to the Law of Contract, Oxford University Press.

Spamann, Holger (2015). "Empirical Comparative Law." Annual Review of Law and Social Science 11: 131-153.

Vanberg, Christoph (2008). "Why Do People Keep their Promises? An Experimental Test of Two Explanations." Econometrica 76(6): 1467-1480.

Wilkinson-Ryan, Tess and David Hoffman (2015). "The Common Sense of Contract Formation." Stanford Law Review 67: 1269-1301. 


\section{Appendix \\ Instructions \\ General Explanations for Participants}

Welcome to our experiment!

If you read the following instructions carefully, depending on your choices you can earn a substantial amount of money. It is therefore important that you read the instructions attentively.

During the experiment, communication with other participants is absolutely forbidden. If you violate this rule, you will be excluded from the experiment and all payments. If you have questions, please put your hand outside the cubicle. We will come to you.

During the experiment, we will not speak of Euro, but of Taler. Hence your entire income is first calculated in Taler. The total amount of Taler that you earn during the experiment will in the end be converted into Euro, with

$$
100 \text { Taler }=1 \text { Euro }
$$

At the end you will be paid out the Taler that you have earned during the experiment in cash. Additionally each participant receives a show up fee of 4 Euro.

\section{Outline of the Experiment}

At the beginning of the experiment, participants are randomly matched to groups of two. Hence you and one other participant are in a group.

In the experiment there are two roles, player $\mathbf{A}$ and player $\mathbf{B}$. It is randomly determined which role you have. Both players are chosen to be player A (or player B) with the same probability: $50 \%$.

Player A receives an endowment of $\mathbf{1 2 0 0}$ Taler. Player B receives an endowment of 0 Taler.

Player A may transfer a fraction of her endowment (between 0 and $100 \%$ ) to player B. Player $\mathrm{B}$ cannot transfer Taler. For each Taler that player A transfers to player B, player B receives two Taler.

Hence if player A transfers X Taler, the income of player A is $\mathbf{1 2 0 0 - X}$ Taler, and the income of player $B$ is $2 * X$ Taler.

Each player may promise to transfer at least $X$ Taler to the other participant in case she becomes player $A$. Note, however, that player $B$ does not have power to enforce this promise. It will be player A's choice whether she wants to keep the promise. 


\section{Course of Events in Detail}

The experiment consists of three stages.

Stage 1: Promise

Stage 2: Decision

Stage 3: Random Draw

\section{Stage 1: Promise}

The computer will only determine at the very end of the experiment who is player $A$ and who is player B. In the first stage, both players may promise to transfer between 0 and $1200 \mathrm{Ta}-$ ler in case they become player $A$.

Specifically you will see the following questions on your screen:

„(1) how many Taler do you promise to transfer to the other player at least if you become player $A$ (irrespective of the promise the other player has given in case she becomes player $\mathrm{A})$ ?“

[Common II treatment additionally]

„(2) how many Taler do you promise to transfer to the other player if the other player in question (1) has promised to transfer at least

.1 Taler

101 Taler

...

1101 Taler?"

If you do not want to make a promise, please write " 0 ". You are completely free to decide whether you want to make a promise.

During later parts of the experiment you will always have a chance to check your responses to these questions. To that end you will see a button "promise" on your screen that you can click with your mouse.

\section{Stage 2: Decision}

In the next stage you decide whether you want to transfer a certain amount to player $B$ in case you will be singled out to be player A. If you become player A, this decision directly affects your income.

Specifically you will see the following question on your screen:

"How many Taler do you transfer to player B in case you are singled out to be player A? (0 to1200)

If you transfer $X$ Taler to player $B$, your income is $\mathbf{1 2 0 0 - X}$ Taler, and the income of player B is $2 * X$ Taler."

[Common I and Common II treatments additionally]

Additionally the other player will be informed about the promise you have made in case you are player $A$. Specifically the other player is informed: 
"The other player has declared that she promises to transfer at least *** Taler in case she becomes player $A$. Note that the other player is free to decide whether she wants to keep this promise."

\section{Questionnaire}

You now can earn additional money. Please answer the following five questions for the purpose.

\section{Question 1}

In stage 1 of the experiment we have asked all participants: how many Taler do you promise to transfer at least to the other player if you become player $A$ ?

What do you think: how many Taler have the participants of this session (you included) on average promised to transfer to the other player? If your estimate is no further away from the true average than $+/-20$ Taler, you receive $1 €$.

\section{Question 2}

In stage 2 of the experiment we have asked all participants: how many Taler do you transfer to player $B$ if you become player $A$ ?

What do you think: how many Taler have the participants of this session (you included) on average transferred to the other player? If your estimate is no further away from the true average than $+/-20$ Taler, you receive $1 €$. 